\title{
The Impact of a Change in Employment on Three Work-Related Diseases: A Retrospective Longitudinal Study of 10,530 Belgian Employees
}

\author{
Laura Maniscalco $^{1, *(\mathbb{C}, \text { Martijn Schouteden }}{ }^{2}$, Jan Boon ${ }^{2} \mathbb{(}$, Domenica Matranga ${ }^{3,+}(\mathbb{C})$ and \\ Lode Godderis $2,4,+(i)$ \\ 1 Department of Biomedicine, Neuroscience and Advanced Diagnostics (BIND), University of Palermo, \\ 90127 Palermo, Italy \\ 2 IDEWE, External Service for Prevention and Protection at Work, 3001 Heverlee, Belgium; \\ Martijn.Schouteden@idewe.be (M.S.); Jan.Boon@idewe.be (J.B.); lode.godderis@kuleuven.be (L.G.) \\ 3 Department of Health Promotion, Maternal-Child Health, Internal and Specialized Medicine of excellence \\ "G. D'Alessandro", University of Palermo, 90127 Palermo, Italy; domenica.matranga@unipa.it \\ 4 KU Leuven, Centre for Environment and Health, 3000 Leuven, Belgium \\ * Correspondence: laura.maniscalco04@unipa.it \\ + The authors contributed in equal measure.
}

Received: 31 August 2020; Accepted: 13 October 2020; Published: 14 October 2020

\begin{abstract}
Background: The literature that has investigated to what extent a change in employment contributes to good health is contradictory or shows inconsistent results. The aim of this study was to investigate whether an association exists between a change in employment and cardiovascular, musculoskeletal and neuropsychological diseases in a sample of 10,530 Belgian workers in a seven-year follow-up study period. Methods: The following factors were analysed: Demographic variables, a change in employment and the work-related risks. Individuals being on medication for cardiovascular, musculoskeletal, and neuropsychological diseases were used as proxies for the three health issues. Logistic regression models for autocorrelated data with repeated measures were used to examine each medication type. Results: A change in employment and psychosocial load can have an important effect on the health of cardiovascular employees. Demographic variables, such as BMI and age, are risk factors for all three medications. Repetitive, manual tasks, handling static, exposure to noise levels of $87 \mathrm{~dB}$, mechanical and/or manual handling with loads, and shift work were found to be positively associated with medications taken for musculoskeletal diseases. Exposure to noise $80 \mathrm{~dB}(\mathrm{~A})$, managing physical loads and night work were found to be associated with being on medication for neuropsychological diseases. Physical activity and skill levels were considered to be protective factors for being on medication for neuropsychological diseases. Conclusions: Change in employment and psychosocial load were found as two important risk factors for being on medication for cardiovascular (CVD). Dealing with loads, doing shift work and being daily exposed to the noise of $87 \mathrm{~dB}$ correlated with being on medication for musculoskeletal (MSD). Dealing with physical loads, doing night work and being exposed to the noise of $80 \mathrm{~dB}$ were risk factors for being on medication for neuropsychological (NPD). While doing physical activity and reporting higher skill levels were found to be protective factors for NPD.
\end{abstract}

Keywords: chronic diseases; cardiovascular diseases; musculoskeletal diseases; neuropsychological diseases; work-related risks 


\section{Introduction}

It is reported that on average people change jobs twelve times during their career. A longitudinal study published by the Bureau of Labour Statistics demonstrated that men had a total of 12.1 jobs and women a total of 11.6 jobs between the ages of 18 and 46. Typically, the main reasons for changing employment are related to: The desire to increase one's pay or to improve one's work-life balance, career advancement, the choice of a less stressful job, incompatibility problems with the boss, and so on [1]. On the contrary, job loss can have a detrimental effect on health as it is negatively associated with: a higher rate of mortality, poor general health, long-standing illness, poorer mental health, psychological distress, and higher hospital admission rates [2,3]. Health and employment influence each other in a reciprocal relationship. Health has a direct influence on work, thus healthy people are more likely to obtain and remain in employment. Conversely, individuals with existing health issues are more likely to be hired for a job with poor working conditions, which in turn can worsen pre-existing health conditions [4,5]. Health also plays an important role in work capabilities, which is influenced by physical and psychosocial demands at work, and by the employees' mental and physical capabilities and lifestyle factors. Disequilibrium between these determinants in suffering ill health could have consequences on work performance, including productivity loss, sickness-related absence, and work-related disabilities [6]. The current literature demonstrates the conflicting results of the effects of employment on health with positive and negative effects [2,7]. One the one hand, employment has been considered as beneficial to health, especially for depression and general mental health because it improves physical and psychological well-being and it provides opportunities to: Increase one's skills, social integration, life goals, prestige and purpose, thereby achieving a sense of personal achievement $[2,8,9]$. Work-related risks that may impact workers' health can be grouped as biological, physical, ergonomic, chemical, and psycho-social. National Institute for Occupational Safety and Health (NIOSH) has reported that there exist 29 kinds of physical, 25 kinds of chemical, 24 kinds of biological, six kinds of ergonomic, and 10 kinds of psychosocial hazards (as work-stress) [10]. Indeed, work can have negative effects on health due to the exposure to health-harming physical and psychosocial stressors, such as: demanding physical work, exposure to various types of harmful radiation, excessive vibration, and high levels of noise and polluted air in the workplace $[8,11]$. Moreover, the nature and quality of work should be taken into account in exploring the relationship with health since the influence of work on health is positive providing that working conditions are favourable; conversely, if employment conditions are poor, then work can impair health $[7,8]$.

Other noteworthy factors are related to changes in employment status and working conditions, which can be repeated throughout one's career. Consequently, the question arises: To what extent does a change in employment contribute to good health? In a sample of Swedish male workers, poor mental health has been found to be weakly associated with the frequency of a change in employment, adjusted for socio-economic status and mediated by general mental health [12]. Another study, in a sample of male employees, found the highest mortality risk in association with a series of changes among unrelated jobs. This sample was retrieved from the Stanford-Terman longitudinal study, an archive containing detailed work and life histories on approximately 1500 men and women. Education, occupation, physical health, anxiety and depression were found as significant risk factors [13]. In a sample of young Dutch subjects, voluntary changes in employment was associated with better health condition. The study included work perceptions (organizational, departmental and task-related as explanatory variables) and job satisfaction, organizational commitment, intention to leave, absenteeism and tardiness as work outcomes [14]. Finally, in a cohort of members of the National Survey of Health and Development, a longitudinal study of people born throughout Britain, it was found that early job changing is an indicator of later psychiatric problems [15].

Conversely, other studies did not find any evidence between frequent job changes in employment and the worker's health status. This result was found for cardiac health in a sample of Scottish employees [16] and myocardial infarction in a case-control study in Sweden [17]. 
Given the controversial nature of these wide-ranging outcome variables, the authors of this study contend that the possible association between frequent changes in employment and health merits further attention. The literature that has investigated to what extent a change in employment contributes to good health is contradictory or shows inconsistent results. For, this reason the aim of this study was to detect whether there exists an association between a change in employment and cardiovascular (CVD), musculoskeletal (MSD) and neuropsychological (NPD) diseases in worker's employed in different sectors in a seven-year follow-up study period. The association between changes in employment and being on medication for the aforementioned work-related diseases will be scrutinised, as proxies for the three health problems, while controlling for work-related risks.

\section{Materials and Methods}

\subsection{Population and Study Design}

The study data were obtained from the largest central repository of data on Belgian employees, the IDEWE data warehouse. IDEWE is the Belgian External Service for Prevention and Protection at Work. IDEWE owns an administrative database, including data from the annual health checks of Belgian employees, and recorded and encoded these data in an electronic format using international or national classification standards [18]. Detailed information about the data collection and data warehouse have been described earlier [18,19]. Periodic health checks in Belgium are mandatory for employees, who are exposed to occupational hazards [20]. In addition to medical data, personal and work characteristics are also registered and encoded during medical examination, using international or national classifications standards in electronic records. Thereafter, the data stored in electronic medical files were extracted, translated and loaded into a data warehouse for further analysis. The study protocol received the ethical approval from the Ethical Committee of Azienda Ospedaliera Policlinico "Paolo Giaccone" of Palermo (Nr. 8/2020, dated 23 September, 2020).

\subsection{Data Collection and Variables}

The final dataset contained 73,710 observations (10,530 employees with at least seven measurement time points between 1993 and 2019) and 24 variables, after removing subjects lacking gender and skill levels. The covariates included in the analysis were: Demographic (age, sex), physical and behavioral characteristics (such as high blood pressure, overweight and obesity measured through BMI, smoking habits), occupational (such as a change in employment, skill levels and sector) and employment-related risk. The medication use response variable was a binary variable with the Not $a$ user category (indicating that a subject in a particular year did not take any medication) and the user category. Since medication compliance is an accurately-encoded registration type in medical files, it was used as a proxy for health status. Limiting the discussion to CVD, it was assumed that an individual took lifelong medication. A "change in employment" is a binary variable with yes or no responses if the employee had not changed employment in that year compared to the previous year. Measured by considering the ISCO-08 code, indicating the work type associated with a particular occupation, skill levels were used as a proxy of educational level. Specifically, the first skill level corresponds to the lowest educational level (primary school), and the second skill level includes employment requiring a secondary education. Occupations classified in the third skill level require a high level of literacy, numeracy and well-developed interpersonal communication skills, and the fourth level requires very high skills, involving an undergraduate or Master's degree and an advanced research qualification. The various employment sectors included 10 major groups: Education, Healthcare, Government, Accommodation and Food Services, Distribution trades, Manufacturing, Services, Construction, Transport and storage, and Other. These categories are based on the official statistical classification of economic activities in the European Community (the NACE code). According to Belgian legislation, occupational physicians perform an individual risk assessment based on information received from the employer and information given by each employee during the medical examination. The occupational 
physician encodes risk factors using an electronic record system, given a list of risk codes that are briefly described using an overview list. This list was designed to allow for the interpretation of the physician, based on his/her own experience and based on the needs of every specific employer or sector at hand. From this list of over 400 risk codes, a small subset was selected by two occupational physicians in an independent way, until consensus was reached. (See Table S1 in Supplementary Materials). For this reason, some risks related to specific employment types were also considered. These were included as yes/no binary variable categories: stress at work, improper or unacceptable behavior at work, work-related exhaustion, noise at work (exposure values of $80 \mathrm{~dB}$, exposure values of $85 \mathrm{~dB}$ and exposure values of $87 \mathrm{~dB}$ ) [21], mechanically and/or manual handling with loads, manual lifting/holding/carrying, manual pulling and/ or pushing, manual repetitive tasks, handling static loads, shift work with and without task-specific risks, night work with and without task-specific risks, and a psychosocial load. The blood pressure was categorized according to the American Heart Association classification. This classification considers both systolic and diastolic blood pressure. The variable was categorized as "Normal", "Elevated", and "High". Elevated for systolic blood pressure between 120-129 and diastolic blood pressure less than 80 and High blood pressure for a systolic pressure more or equal than 140 and a diastolic pressure more or equal than 90 . Smoking habits were classified as "No" if the subject were not a user or a former user, and "Yes" if the subject was currently a smoker.

\subsection{Statistical Methods}

Continuous variables were summarized as a mean value ( $\mathrm{SD}=$ standard deviation), and categorical variables were analyzed as counts and percentages. In order to assess the statistical significance of this difference, the Chi-squared test was used for categorical variables (or Fisher exact test when necessary), and the t-test was used for continuous variables. In order to assess the relationship between a change in employment and medication use (while controlling for the time-variant and time-invariant confounders), a logistic regression model for autocorrelated data with repeated measures was used for each type of medication relating to cardiovascular, musculoskeletal and neuropsychological diseases [22]. For all categorical variables, the no category was used as reference, and separate models were stratified by gender. A backwards, stepwise selection process with the Akaike information criterion (AIC) for model selection was also deployed and the block bootstrap method was used to generate confidence intervals. For the sake of simplicity, in the multivariable analysis only coefficients with significant $p$-values were reported. The data were analyzed using $R$ software, version 3.5.1 including the Bild packages (version 1.1). A $p$-value less than 0.05 was considered statistically significant.

\section{Results}

\subsection{Descriptive Statistics}

Table 1 shows the results of the descriptive analyses. The sample included 4769 (45\%) females and $5761(55 \%)$ males. The mean age of females was higher compared to that of males (Female: $38.89 \pm 9.36$; Male: $37.56 \pm 9.77$ ), while BMI was on average higher for males (BMI: $26.08 \pm 4.15$ ) when compared to females (BMI: $25.27 \pm 4.86$ ). The blood pressure variable was distributed differently between males and females: at baseline $73 \%$ of males, compared to $52 \%$ of females, suffered from high blood pressure. Typically, both males and females were not smokers at baseline during the data collection period. The distribution by activity sector and gender revealed that $40.8 \%$ of males worked in the manufacturing sector, followed by $15 \%$ in the government, $10.7 \%$ in distribution trades and $10.3 \%$ of males worked in the healthcare sector. Whereas, the distribution of female employees by sector was the following: $74.6 \%$ worked for the healthcare sector, $9.2 \%$ for government and $6.6 \%$ in the manufacturing sector. The majority of males were characterized by the second skill level $(74 \%)$, while most females reporting the third or fourth skill level (42\%). At baseline few males and females were affected by stress at work and exhaustion due to employment-related risks. The majority of males were subjected to daily noise levels of $87(\mathrm{~dB})(51 \%)$, as were males and females regarding manual load-handling 
(59\% for males, $88 \%$ for females). Considering that the study is a retrospective (historical) cohorts percentage of people exposed to daily noise levels of $87 \mathrm{~dB}$ could appear oversized. At univariable analysis, male employees changing employment versus those who did not show differences in: BMI, stress at work, work-related exhaustion, noise levels of $85 \mathrm{~dB}$ or $87 \mathrm{~dB}$, mechanically and/or manual handling with loads, holding, carrying, handling static loads, shift work without task-specific risks and psychosocial loads. Similarly, female employees who changed employment versus those who did not displayed differences in: BMI, skill level, static load, shift work (with and without task-specific risks), night work (without task-specific risk) and psychosocial loads. At baseline, $2 \%$ of males were medication compliant for MSD, compared to $4 \%$ of females ( $p$-value $<0.0001$ ); $7 \%$ of males and $7 \%$ of females $(p$-value $=0.418)$ were medication compliant for CVD; $2 \%$ of males compared to $5 \%$ female users ( $p$-value < 0.0001) (Table 2 ) were medication compliant for NPD.

Table 1. Baseline characteristics 10530 Belgian workers by gender.

\begin{tabular}{|c|c|c|c|}
\hline Variables & Male & Female & $p$-Value \\
\hline Age, mean (SD) & $37.56(9.77)$ & $38.89(9.36)$ & $<0.0001$ \\
\hline BMI, mean (SD) & $26.08(4.15)$ & $25.27(4.86)$ & $<0.0001$ \\
\hline \multicolumn{4}{|l|}{ Blood pressure } \\
\hline Normal & $682(12 \%)$ & $1456(31 \%)$ & \multirow{3}{*}{$<0.0001$} \\
\hline Elevated & $879(15 \%)$ & $856(18 \%)$ & \\
\hline High & $4200(73 \%)$ & $2457(52 \%)$ & \\
\hline \multicolumn{4}{|l|}{ Smoking habits } \\
\hline No & $3784(66 \%)$ & $3735(78 \%)$ & \multirow{2}{*}{$<0.0001$} \\
\hline Yes & $1977(34 \%)$ & $1034(22 \%)$ & \\
\hline \multicolumn{4}{|l|}{ Sector } \\
\hline Education & $74(1.3 \%)$ & $144(3.0 \%)$ & \multirow{10}{*}{$<0.0001$} \\
\hline Healthcare & $592(10.3 \%)$ & $3558(74.6 \%)$ & \\
\hline Government & $862(15.0 \%)$ & $437(9.2 \%)$ & \\
\hline Food & $23(0.4 \%)$ & $47(1.0 \%)$ & \\
\hline Distributive trade & $618(10.7 \%)$ & $138(2.9 \%)$ & \\
\hline Manufacturing & $2349(40.8 \%)$ & $316(6.6 \%)$ & \\
\hline Services & $162(2.8 \%)$ & $54(1.1 \%)$ & \\
\hline Construction & $542(9.4 \%)$ & $1(0.0 \%)$ & \\
\hline Transport & $209(3.6 \%)$ & $17(0.4 \%)$ & \\
\hline Other & $330(5.7 \%)$ & $57(1.2 \%)$ & \\
\hline \multicolumn{4}{|l|}{ Skill levels } \\
\hline 1 & $448(8 \%)$ & $1146(24 \%)$ & \multirow{3}{*}{$<0.0001$} \\
\hline 2 & $4281(74 \%)$ & $1627(34 \%)$ & \\
\hline 3 or 4 & $1032(18 \%)$ & $1996(42 \%)$ & \\
\hline \multicolumn{4}{|l|}{ Risk: stress at work } \\
\hline No & $5759(99.9 \%)$ & $4768(99.9 \%)$ & \multirow[b]{2}{*}{1} \\
\hline Yes & $2(0.01 \%)$ & $1(0.01 \%)$ & \\
\hline \multicolumn{4}{|l|}{ Risk: burnout } \\
\hline No & $5761(100 \%)$ & $4769(100 \%)$ & \multirow{2}{*}{1} \\
\hline Yes & $0(0 \%)$ & $0(0 \%)$ & \\
\hline \multicolumn{4}{|l|}{ Risk: noise $87(\mathrm{~dB})$} \\
\hline No & $2813(49 \%)$ & $4534(95 \%)$ & \multirow{2}{*}{$<0.0001$} \\
\hline Yes & $2948(51 \%)$ & $235(5 \%)$ & \\
\hline
\end{tabular}


Table 1. Cont.

\begin{tabular}{|c|c|c|c|}
\hline Variables & Male & Female & $p$-Value \\
\hline \multicolumn{4}{|c|}{ Risk: noise $85(\mathrm{~dB})$} \\
\hline No & $5451(95 \%)$ & $4743(99 \%)$ & \multirow{2}{*}{$<0.0001$} \\
\hline Yes & $310(5 \%)$ & $26(1 \%)$ & \\
\hline \multicolumn{4}{|c|}{ Risk: noise $80(\mathrm{~dB})$} \\
\hline No & $5661(98 \%)$ & $4749(99 \%)$ & \multirow{2}{*}{$<0.0001$} \\
\hline Yes & $100(2 \%)$ & $20(1 \%)$ & \\
\hline \multicolumn{4}{|c|}{ Risk: Mechanical handling with loads } \\
\hline No & $5457(95 \%)$ & $4636(97 \%)$ & \multirow{2}{*}{$<0.0001$} \\
\hline Yes & $304(5 \%)$ & $133(3 \%)$ & \\
\hline \multicolumn{4}{|c|}{ Risk: Manual handling with loads } \\
\hline No & $2338(41 \%)$ & $560(12 \%)$ & \multirow{2}{*}{$<0.0001$} \\
\hline Yes & $3423(59 \%)$ & $4209(88 \%)$ & \\
\hline \multicolumn{4}{|c|}{ Risk: Manual lifting, holding, carrying } \\
\hline No & $5761(100 \%)$ & $4769(100 \%)$ & \multirow{2}{*}{1} \\
\hline Yes & $0(0 \%)$ & $0(0 \%)$ & \\
\hline \multicolumn{4}{|c|}{ Risk: Manual pulling and pushing } \\
\hline No & $5761(100 \%)$ & $4769(100 \%)$ & \multirow[b]{2}{*}{1} \\
\hline Yes & $0(0 \%)$ & $0(0 \%)$ & \\
\hline \multicolumn{4}{|c|}{ Risk: Manual repetitive tasks } \\
\hline No & $5761(100 \%)$ & $4769(99.9 \%)$ & \multirow[b]{2}{*}{1} \\
\hline Yes & $0(0 \%)$ & $0(0.01 \%)$ & \\
\hline \multicolumn{4}{|c|}{ Risk: Handling static load } \\
\hline No & $5696(99 \%)$ & $4750(99 \%)$ & \multirow{2}{*}{$<0.0001$} \\
\hline Yes & $65(1 \%)$ & $19(1 \%)$ & \\
\hline \multicolumn{4}{|c|}{ Risk: Shift work without task-specific risk } \\
\hline No & $4995(87 \%)$ & $4317(91 \%)$ & \multirow{2}{*}{$<0.0001$} \\
\hline Yes & $766(13 \%)$ & $452(9 \%)$ & \\
\hline \multicolumn{4}{|c|}{ Risk: Shift work with task-specific risk } \\
\hline No & $5498(95 \%)$ & $4645(97 \%)$ & \multirow{2}{*}{$<0.0001$} \\
\hline Yes & $263(5 \%)$ & $124(3 \%)$ & \\
\hline \multicolumn{4}{|c|}{$\begin{array}{c}\text { Risk: Night work without task-specific } \\
\text { risk }\end{array}$} \\
\hline No & $5515(96 \%)$ & $4585(96 \%)$ & \multirow{2}{*}{0.31} \\
\hline Yes & $246(4 \%)$ & $184(4 \%)$ & \\
\hline \multicolumn{4}{|c|}{ Risk: Night work with task-specific risk } \\
\hline No & $5626(98 \%)$ & $4701(99 \%)$ & \multirow{2}{*}{$<0.0001$} \\
\hline Yes & $135(2 \%)$ & $68(1 \%)$ & \\
\hline \multicolumn{4}{|c|}{ Risk: Psychosocial load } \\
\hline No & $5579(97 \%)$ & $4637(97 \%)$ & \multirow{2}{*}{0.263} \\
\hline Yes & $182(3 \%)$ & $132(3 \%)$ & \\
\hline
\end{tabular}

$p$-values from t-test for continuous variables and Chi-squared tests (or Fisher exact test when necessary) for categorical variables. Continuous variables are expressed as mean and SD and categorical variables as $\mathrm{n}$ and percentage. Elevated blood pressure: $120 \leq$ Systolic $\leq 129$ \& Diastolic $<80$; High blood pressure: Systolic $\geq 140 \&$ Diastolic $\geq 90$. 
Table 2. Baseline characteristics medication use of 10530 Belgian workers by gender.

\begin{tabular}{cccc}
\hline Variables & Male & Female & $p$-Value \\
\hline Being on medication for MSD & & & \\
\hline No & $5325(98 \%)$ & $4592(96 \%)$ & $<0.0001$ \\
Yes & $136(2 \%)$ & $177(4 \%)$ & \\
\hline Being on medication for CVD & & & \multirow{2}{*}{0.418} \\
No & $5371(93 \%)$ & $4426(93 \%)$ & \\
Yes & $390(7 \%)$ & $343(7 \%)$ & $<0.0001$ \\
\hline Being on medication for NPD & & & \\
\hline No & $5625(98 \%)$ & $4530(95 \%)$ & \\
\hline Chi-squared tests were used & $136(2 \%)$ & $239(5 \%)$ & \\
\hline
\end{tabular}

\subsection{Being on Medication for MSD}

BMI, age and performing manual, repetitive tasks were found to be positively associated with being on medication for MSD for males and females. Indeed, an increase in these variables corresponded to a higher probability of medication use. A change in employment did not seem to be associated to MSD for males and females. In addition to the aforementioned MSD variables, the following increased the probability reporting MSD in males: Exposure to noise $87 \mathrm{~dB}$ level, dealing with physical load, manual handling with loads and shift work (OR $=1.22$ 95\% CI [1.04-1.40], OR = 1.25 95\%CI [1.05-1.47], $\mathrm{OR}=1.2195 \% \mathrm{CI}[1.03-1.42]$ and $\mathrm{OR}=1.7095 \% \mathrm{CI}$ [1.29-2.11] respectively). In contrast, doing physical activity and manual lifting reduced the probability to be on medication for MSD (OR $=0.8595 \% \mathrm{CI}$ [0.75-0.95], and $0.3395 \% \mathrm{CI}$ [0.22-0.38] respectively). The risk for females dealing with static loads at work increased the risk of being a medication user (OR $=1.6295 \% \mathrm{CI}[1.22-2.11])$ whereas the manual dealing with loads was found to be a protective factor (OR $=0.79$ 95\%CI [0.68-0.95]) (Table 3).

Table 3. Logistic regression model for being on medication for MSD by gender.

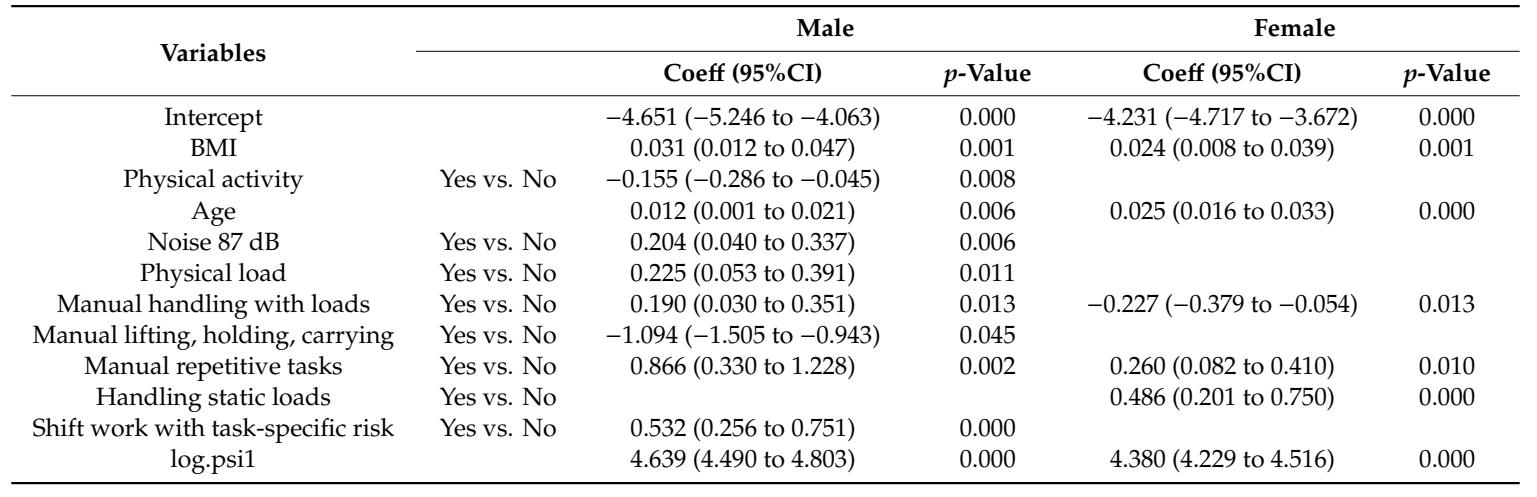

\subsection{Being on Medication for $C V D$}

A change in employment seemed to have a significant effect on the response variable for both genders $(\mathrm{OR}=1.9395 \% \mathrm{CI}$ [1.47-2.78] for males and $\mathrm{OR}=1.8695 \% \mathrm{CI}$ [1.34-2.50] for females). This implies that the probability of those changing employment to be on medication for cardiovascular diseases was approximately $93 \%$ and $86 \%$ for males and females respectively, and this is higher than the odds for those who do not change employment after controlling for other explanatory variables. Moreover, BMI, age and psychosocial pressure were found to be significant for being on medication for CVD. Indeed, the psychosocial load seems to increase the probability of being on medication for CVD with $\mathrm{OR}=1.23(95 \% \mathrm{CI}[1.07-1.38])$ for males and OR $=1.21$ (95\%CI [1.09-1.32]) for females. In addition to the aforementioned variables, the following were positively associated with CVD in males: stress at 
work, noise levels of $80 \mathrm{~dB}(\mathrm{~A})$, manual handling with loads in the workplace, dealing with static loads, shift work (without task-specific risks) and night work (with and without task-specific risks). Moreover, smoking played a confounding role as non-smokers in the study sample were over-represented with respect to smokers (2.5:1). However, the model for females showed that dealing with physical loads as positively associated with the response variable (Table 4 ).

Table 4. Logistic regression model for being on medication for CVD by gender.

\begin{tabular}{|c|c|c|c|c|c|}
\hline \multirow{2}{*}{ Variables } & \multicolumn{3}{|c|}{ Male } & \multicolumn{2}{|l|}{ Female } \\
\hline & & Coeff $(95 \% \mathrm{CI})$ & $p$-Value & Coeff $(95 \% \mathrm{CI})$ & $p$-Value \\
\hline Intercept & & $-6.483(-6.949$ to -6.038$)$ & 0.000 & $-6.517(-6.932$ to -6.091$)$ & 0.000 \\
\hline BMI & & 0.049 (0.035 to 0.064$)$ & 0.000 & $0.053(0.044$ to 0.062$)$ & 0.000 \\
\hline \multirow[t]{2}{*}{ Blood pressure } & $\begin{array}{l}\text { Elevated vs. } \\
\text { Normal }\end{array}$ & $-0.019(-0.061$ to 0.018$)$ & 0.465 & $-0.013(-0.051$ to 0.022$)$ & 0.570 \\
\hline & $\begin{array}{l}\text { High Blood } \\
\text { vs. Normal }\end{array}$ & $-0.032(-0.069$ to -0.002$)$ & 0.159 & $0.009(-0.023$ to 0.045$)$ & 0.628 \\
\hline Smoking habits & Yes vs. No & $-0.211(-0.299$ to -0.123$)$ & 0.000 & & \\
\hline Age & & $0.076(0.068$ to 0.084$)$ & 0.000 & $0.076(0.067$ to 0.086$)$ & 0.000 \\
\hline $\begin{array}{c}\text { Change in employment (Yes } \\
\text { vs. No) }\end{array}$ & & $0.660(0.389$ to 1.023$)$ & 0.000 & $0.622(0.294$ to 0.918$)$ & 0.000 \\
\hline Stress at work & Yes vs. No & $0.207(0.024$ to 0.388$)$ & 0.033 & & \\
\hline Noise $80 \mathrm{~dB}$ & Yes vs. No & $0.120(-0.036$ to 0.241$)$ & 0.043 & & \\
\hline Physical load & Yes vs. No & & & $0.101(0.023$ to 0.189$)$ & 0.039 \\
\hline Manual handling with loads & Yes vs. No & $0.149(0.080$ to 0.230$)$ & 0.000 & & \\
\hline Static load & Yes vs. No & $0.273(0.134$ to 0.415$)$ & 0.000 & & \\
\hline $\begin{array}{l}\text { Shift work without } \\
\text { task-specific risk }\end{array}$ & Yes vs. No & 0.168 (0.085 to 0.251$)$ & 0.000 & & \\
\hline $\begin{array}{l}\text { Night work without } \\
\text { task-specific risk }\end{array}$ & Yes vs. No & $0.166(0.035$ to 0.312$)$ & 0.012 & & \\
\hline $\begin{array}{c}\text { Night work with task-specific } \\
\text { risk }\end{array}$ & Yes vs. No & 0.167 (-0.041 to 0.307$)$ & 0.049 & & \\
\hline Psychosocial load & Yes vs. No & $0.214(0.073$ to 0.326$)$ & 0.001 & $0.193(0.087$ to 0.278$)$ & 0.000 \\
\hline log.psi1 & & $7.128(7.004$ to 7.318$)$ & 0.000 & $7.039(6.902$ to 7.206$)$ & 0.000 \\
\hline
\end{tabular}

Elevated blood pressure: $120 \leq$ Systolic $\leq 129$ \& Diastolic $<80$; High blood pressure: Systolic $\geq 140$ \& Diastolic $\geq 90$.

\subsection{Being on Medication for NPD}

To be on medication for NPD was significantly associated with age (OR $=1.0295 \% \mathrm{CI}$ [1.01-1.03] for male, $\mathrm{OR}=1.0195 \% \mathrm{CI}$ [1.01-1.02] for female), negatively associated with physical activity (OR $=0.83$ $95 \%$ CI [0.74-0.94] for male, OR $=0.8695 \%$ CI [0.78-0.96] for female). Furthermore, males with skill level 3 or 4 were protected compared to skill level 1 (OR $=0.6395 \% \mathrm{CI}[0.40-0.99]$ ) and both males and females with skill level 2 were protected, compared to individuals with a skill level 1 (OR $=0.58$ 95\%CI [0.42-0.89] for male, $\mathrm{OR}=0.7795 \% \mathrm{CI}$ [0.60-0.99] for female). Moreover, BMI, noise levels of $80 \mathrm{~dB}(\mathrm{~A})$, night work (without risks) were also associated with being on medication for NPD in the male sample. Specifically, noise levels of $80 \mathrm{~dB}(\mathrm{~A})$ and night work (without task-specific risk) increased the probability of being on medication for NPD (OR $=1.5895 \% \mathrm{CI}[1.20-2.03]$ and $\mathrm{OR}=1.3495 \% \mathrm{CI}$ [1.01-1.79] respectively). However, an increase in BMI decreased the probability of reporting NPD. The following was found to increase the probability of being on medication for NPD in females: History of smoking, dealing with physical loads in the workplace and doing night shifts (with task-specific risk). Furthermore, female employees in the healthcare and government sectors presented higher risks associated with being on medication for NPD, compared to female employees in the education sector ( $\mathrm{OR}=2.20$ 95\%CI [1.24-4.31], and 2.35 95\%CI [1.20-5.08], respectively) (Table 5). 
Table 5. Logistic regression model for being on medication for NPD by gender.

\begin{tabular}{|c|c|c|c|c|c|}
\hline \multirow{2}{*}{ Variables } & & \multicolumn{2}{|l|}{ Male } & \multicolumn{2}{|l|}{ Female } \\
\hline & & Coeff $(95 \% \mathrm{CI})$ & $p$-Value & Coeff $(95 \% \mathrm{CI})$ & $p$-Value \\
\hline Intercept & & $-3.055(-3.849$ to -2.391$)$ & 0.000 & $-4.080(-4.800$ to -3.355$)$ & 0.000 \\
\hline BMI & & $-0.019(-0.041$ to 0.004$)$ & 0.058 & & \\
\hline Sport & Yes vs. No & $-0.179(-0.302$ to -0.058$)$ & 0.002 & $-0.144(-0.242$ to -0.040$)$ & 0.002 \\
\hline Smoking habits & Yes vs. No & & & 0.361 (0.189 to 0.539$)$ & 0.000 \\
\hline Age & & 0.020 (0.009 to 0.032$)$ & 0.000 & 0.017 (0.007 to 0.028$)$ & 0.000 \\
\hline Skill level & $\begin{array}{c}2 \text { vs. } 1 \\
3 \text { or } 4 \text { vs. } 1\end{array}$ & $\begin{array}{l}-0.532(-0.855 \text { to }-0.113) \\
-0.466(-0.915 \text { to }-0.005)\end{array}$ & $\begin{array}{l}0.001 \\
0.013\end{array}$ & $\begin{array}{c}-0.251(-0.506 \text { to }-0.008) \\
-0.115(-0.356 \text { to } 0.151)\end{array}$ & $\begin{array}{l}0.030 \\
0.298\end{array}$ \\
\hline Sector & $\begin{array}{l}\text { Healthcare vs. Education } \\
\text { Government vs. Education } \\
\text { Food vs. Education } \\
\text { Distributive trade vs. Education } \\
\text { Manufacturing vs. Education } \\
\text { Services vs. Education } \\
\text { Transport vs. Education } \\
\text { Other vs. Education }\end{array}$ & & & $\begin{array}{c}0.789(0.220 \text { to } 1.461) \\
0.858(0.190 \text { to } 1.626) \\
0.849(-0.952 \text { to } 2.014) \\
0.116(-0.732 \text { to } 0.917) \\
0.679(-0.045 \text { to } 1.363) \\
0.271(-2.353 \text { to } 1.425) \\
0.723(-0.892 \text { to } 1.658) \\
0.588(-7.639 \text { to } 2.052)\end{array}$ & $\begin{array}{l}0.003 \\
0.003 \\
0.081 \\
0.781 \\
0.050 \\
0.609 \\
0.354 \\
0.212\end{array}$ \\
\hline Noise $80 \mathrm{~dB}$ & Yes vs. No & $0.458(0.185$ to 0.709$)$ & 0.001 & & \\
\hline Physical load & Yes vs. No & & & 0.227 (0.034 to 0.396$)$ & 0.014 \\
\hline Night work without task-specific risk & Yes vs. No & $0.296(0.012$ to 0.583$)$ & 0.033 & & \\
\hline Night work with task-specific risk & Yes vs. No & & & $0.443(0.012$ to 0.787$)$ & 0.008 \\
\hline log.psi1 & & $5.722(5.530$ to 5.916$)$ & 0.000 & 5.039 (0.012 to 0.787$)$ & 0.000 \\
\hline
\end{tabular}

Elevated blood pressure: $120 \leq$ Systolic $\leq 129$ \& Diastolic $<$ 80; High blood pressure: Systolic $\geq 140$ \& Diastolic $\geq 90$. 


\section{Discussion}

The aim of this work was to assess whether an association exists between a change in employment and the use of medication for three work-related diseases: Cardiovascular, musculoskeletal and neuropsychological. These subjects were then followed up in a seven-year period, while they were in employment. To this aim, a large data warehouse obtained from IDEWE, a Belgian External Service for Prevention and Protection at Work, was deployed. The application of three logistic regression models for autocorrelated data revealed important results.

Exposure to risk factors can lead to MSD over extended periods of time but it is highly improbable that the results of a change in employment would have an immediate effect on MSD. Due to their non-specific nature, MSDs are often significantly under-reported in the literature. Moreover, it has been documented that some social security records are subject to a prolonged time delay between the initial declaration and recognition of MSD [23]. This study is for MSDs in line with the literature. Individual factors such as BMI, age and physical activity are associated with MSDs [23] and other work-related risk factors include: Unnatural posture, repetitive strain injury, physical exertion, static work; being subject to excessive vibrations, work overload, stress and other psychosocial factors can all contribute to the onset of those disorders [24]. The sectors mentioned in this study were not statistically significant for MSDs and it is posited that this may be due to the nature of the sample composition. Indeed, IDEWE mainly collects data from employees who work in the healthcare sector. Furthermore, it has been demonstrated elsewhere that agriculture, health and social work, transport storage and communication sectors were more frequently associated with MSD [23]. Lifting and especially lifting of heavy loads, sedentary work and physical inactivity have been found to contribute to back pain. The protective role of manual handling with loads for being on medication for MSD may well be due to "healthy worker effects" and uncontrolled confounding. Many authors believe that work strain mediates the association between work stressors and work-related musculoskeletal complaints, whereby the mental and physical mechanisms involved elicit muscle tension and induce musculoskeletal pain [25].

An important issue regarding being on medication for CVD is due to the deteriorating role of changes in employment, as confirmed by Haynes S. [26]. This is due to the fact that individuals who experienced frequent changes in employment are more likely to smoke, to consume excess alcohol, and to do less physical activity [15]. Moreover, this study found that increasing age is a significant risk factor for CVD, as also confirmed by the WHO [27]. Furthermore, it has been asserted that a higher skill level reduces the probability of being on medication for CVD, even if not significant in this study. In line with the results of the Belgian Job Stress Project [28], psychosocial pressure was found a determinant of being on medication for CVD. Indeed, the WHO have found the following to be associated with an increased risk of being on medication CVD: Mental pressure at work, psychosocial stress, sedentary work, chronic exposure to excessive levels of noise and other occupational factors [27,29]. Our study found that physical load, manual handling with loads and static load are risk factors for CVD. This is in accordance with Hannerz and Holtermann's study where employment in occupations that involve heavy lifting is a predictor of Ischemic Heart Disease [30]. Other studies also reported a positive relationship between shiftwork and coronary heart disease, possibly due to irregular working hours or unbalanced lifestyle [27].

The lack of association between a change in employment and being on medication for NPD could be due to the social stigma and consequent under-reporting of disease [31]. This implies a structural discrimination in workplace settings since individuals with mental illness tend to have reduced access to quality jobs and they are less likely to be perceived as being suitable for promotion [32]. While, it is likely that people with mental health issues may change their employment, in order to reduce workload, stress and responsibility, the opposite is not necessarily true. It is unlikely that a change in employment may be associated with employees recovering from mental issues since these are often chronic in nature [33]. Undertaking physical activity and higher skill levels were found to be protective factors [34], while age is a risk factors for mental health in this study and this is in line with the findings 
of the WHO. The presence of respiratory system complaints caused by smoking habits was found to be an important risk factor for a broad category of mental disease as anxiety, depression, and the combination of anxiety and depression [35].

The study found the following risk factors for being on medication for NPD: dealing with physical loads and night work (with task-specific risks) for women, and night work (without task-specific risks) and excessive daily noise at work for men. It seems that psychological ill health is worse for female employees in the healthcare and government sectors as compared to female non-healthcare employees (for example, those working in the education sector). This is in accordance with Stansfeld et al. that demonstrated that the type of occupation is an important risk factor for common mental disorders. It occurs because "occupations may be typified by high levels of job demands, especially emotional demands and lack of job security. The reasons why occupations have low rates of common mental disorder are varied and may include high levels of job discretion, good job training and clearly defined job tasks" [36]. An intervention study, which has been included in the literature review, has demonstrated that aerobic exercise is associated with improved health [37], and a Canadian population-based longitudinal study concluded that work-related stress is the major risk of depressive episodes [38]. The same Canadian authors also stated that the impact of risk factors may vary across genders since the impact of work stressors on common mental disorders in their review differed for males and females [38]. Mental health is demonstrated to be negatively correlated with the constant high physical and psychosocial work demands [39]. A study conducted by the WHO regarding healthcare employees showed that an excessive workload is a risk factor for mental health, and the authors of this paper observed that smoking can increase neuropsychological medication use in women [40].

The main strength of the paper is the availability of a seven-year follow-up study period, in order to investigate the association between job changes and three different diseases, while considering a wealth of work-related risk factors. Conversely, there are a few study limitations. First of all, the drop-out of employees that leave their job or change it, with the effect to be lost to follow up, because they are no longer enrolled in the same OSH provider (IDEWE). Moreover, the specific causes of job changes are not considered, so the occurrence of some confounding in the analysis cannot be excluded. Other important potential risk factors such as diet, work satisfaction, and sickness absence, family life, supportive relationships with colleagues, economic security, and access to social support were not measured. Self-reported information on smoking habits was potentially underreported and some risks as burnout, conflicts with customers, safety risk and hindrance were excluded to avoid sparseness in the models, since they presented very few observations.

\section{Conclusions}

The aim of this study was to explore the effect of changes in employment on the health of employees, while considering a series of risk factors associated with work-related diseases. This association was found to be statistically significant and positive only for CVD, excluding the effect of other covariates. Moreover, psychosocial loads also play an important role in the onset of CVD. Regarding medication for MSD, a positive association was found with BMI, age, manual and repetitive tasks, the handling of static loads, noise exposure of $87 \mathrm{~dB}$, mechanical and/or manual handling with loads, and shift work. Finally, being on medication for NPD showed significant positive association with age, BMI, smoking habits, noise of $80 \mathrm{~dB}(\mathrm{~A})$, dealing with physical loads and night work (without task-specific risk), while doing physical activity and reporting higher skill levels were found to be protective factors. As a consequence, it is recommended that the employer's working life is tracked by recording his/her job changes. In fact, the worsening of the worker's health reflects in lower productivity, augmented cost for the employer and affects public health. Our study showed an increased risk of cardiovascular disease in Belgian workers who experience a job change. Therefore, it is advisable, especially in the transition phases between one job and another, that the worker's health status is monitored by the general practitioner and the occupational physician. 
Supplementary Materials: The following are available online at http://www.mdpi.com/1660-4601/17/20/7477/s1, Table S1: List of risk factors.

Author Contributions: Conceptualization, D.M. and L.G.; methodology, L.M.; software, L.M.; validation, D.M. and L.G.; formal analysis, L.M.; data curation, M.S. and J.B.; writing—original draft preparation, L.M.; writing-review and editing, L.M., D.M. and L.G.; visualization, L.M.; supervision, D.M. and L.G. All authors have read and agreed to the published version of the manuscript.

Funding: This research received no external funding.

Conflicts of Interest: Martijn Schouteden, Jan Boon and Lode Godderis collaborate with IDEWE.

\section{References}

1. National Longitudinal Survey Program. Number of Jobs, Labor Market Experience, and Earnings Growth: Results from a National Longitudinal Survey News Release; U.S. Bureau of Labor Statistics: Washington, DC, USA, 2010.

2. Goodman, N. The Impact of Employment on the Health Status and Health Care Costs of Working-Age People with Disabilities; Lead Center: Washington, DC, USA, 2015.

3. Waddell, G.; Burton, A.K. Is Work Good for Your Health and Well-Being? The Stationery Office: Norwhich, UK, 2006.

4. Korpi, T. Accumulating Disadvantage: Longitudinal Analyses of Unemployment and Physical Health in Representative Samples of the Swedish Population. Eur. Sociol. Rev. 2001, 17, 255-273. [CrossRef]

5. Schur, L.A. Barriers or Opportunities? The Causes of Contingent and Part-time Work among People with Disabilities. Ind. Relat. 2003, 42, 589-622. [CrossRef]

6. Alavinia, S.M. The Effect of Work on Health and Work Ability. Ph.D. Thesis, Erasmus University of Rotterdam, Rotterdam, The Netherlands, 2008.

7. Dodu, N. Is employment good for well-being? A literature review. J. Occup. Psychol. Employ. Disabil. 2005, 7, 17-33.

8. van der Noordt, M.; IJzelenberg, H.; Droomers, M.; Proper, K.I. Health effects of employment: A systematic review of prospective studies. Occup. Environ. Med. 2014, 71, 730-736. [CrossRef]

9. Maniscalco, L.; Miceli, S.; Bono, F.; Matranga, D. Self-Perceived Health, Objective Health, and Quality of Life among People Aged 50 and Over: Interrelationship among Health Indicators in Italy, Spain, and Greece. Int. J. Environ. Res. Public Health 2020, 17, 2414. [CrossRef]

10. About "NIOSH". Centers for Disease Control and Prevention. Available online: https://www.cdc.gov/ (accessed on 21 September 2020).

11. Burgard, S.A.; Lin, K.Y. Bad jobs, bad health? How work and working conditions contribute to health disparities. Am. Behav. Sci. 2013, 57, 1105-1127. [CrossRef]

12. Isaksson, K.A. longitudinal study of the relationship between frequent job change and psychological well-being. J. Occup. Psychol. 1990, 63, 297-308. [CrossRef]

13. Pavalko, E.; Elder, G., Jr.; Clipp, E. Worklives and Longevity: Insights from a Life Course Perspective. J. Health Soc. Behav. 1993, 34, 363-380. [CrossRef]

14. Van der Velde, M.E.; Feij, J.A. Change of work perceptions and work outcomes as a result of voluntary and involuntary job change. J. Occup. Organ. Psychol. 1995, 68, 273-290. [CrossRef]

15. Cherry, N. Persistent job changing-Is it a problem? J. Occup. Psychol. 1976, 49, 203-221. [CrossRef]

16. Metcalfe, C.; Smith, G.D.; Sterne, J.A.; Heslop, P.; Macleod, J.; Hart, C. Frequent job change and associated health. Soc. Sci. Med. 2003, 56,1-15. [CrossRef]

17. Theorell, T. Life events before and after the onset of a premature myocardial infarction. In Stressful Life Events: Their Nature and Effects; Dohrenwend, B.S., Dohrenwend, B.P., Eds.; John Wiley \& Sons: New York, NY, USA, 1974.

18. Godderis, L.; Mylle, G.; Coene, M.; Verbeek, C.; Viaene, B.; Bulterys, S.; Schouteden, M. Data warehouse for detection of occupational diseases in OHS data. Occup. Med. 2015, 65, 651-658. [CrossRef] [PubMed] 
19. Bosson-Rieutort, D.; Schouteden, M.; Godderis, L.; Bicout, D.J. Observational Surveillance Approach to Detect Novel Work-Related Diseases and Hazards: An Application to a Belgian Occupational Health and Safety Database. J. Occup. Environ. Med. 2018, 60, e476-e483. [CrossRef]

20. Godderis, L.; Johannik, K.; Mylle, G.; Bulterys, S.; Moens, G. Epidemiological and performance indicators for occupational health services: A feasibility study in Belgium. BMC Health Serv. Res. 2014, 14, 410. [CrossRef] [PubMed]

21. European Agency for Safety \& Health at Work. Magazine of the European Agency for Safety and Health at Work; No. 1. Office for Official Publications of the European Communities: Luxembourg, 1999.

22. Gonçalves, M.H.; Cabral, M.S.; Azzalini, A. TheRPackagebildfor the Analysis of Binary Longitudinal Data. J. Stat. Softw. 2012, 46,1-17. [CrossRef]

23. Parent-Thirion, A.; Fernández Macías, E.; Hurley, J.; Vermeylen, G. Fourth European Working Conditions Survey, European Foundation for the Improvement of Living and Working Conditions; Office for Official Publications of the European Communities: Luxembourg, 2007; pp. 37-61.

24. Health and Safety Executive. Upper Limb Disorders in the Workplace; HSE Books: Sudbury, UK, 2002.

25. Elfering, A.; Igic, I.; Keller, A.C.; Meier, L.L.; Semmer, N.K. Work-privacy conflict and musculoskeletal pain: A population-based test of a stress-sleep-mediation model. Health Psychol. Behav. Med. 2016, 4, 70-90. [CrossRef]

26. Haynes, S.; Feinleib, M.; Kannel, W.B. The relationship of psychosocial factors to coronary heart disease in the Framingham Study. III. Eight-year incidence of coronary heart disease. Am. J. Epidemiol. 1980, 111, 37-58. [CrossRef]

27. World Health Organization. Epidemiology of Work Related Diseases and Accidents; World Health Organization: Geneva, Switzerland, 1989.

28. De Bacquer, D.; Pelfrene, E.; Clays, E.; Mak, R.; Moreau, M.; De Smet, P.; Kornitzer, M.; De Backer, G. Perceived Job Stress and Incidence of Coronary Events: 3-Year Follow-up of the Belgian Job Stress Project Cohort. Am. J. Epidemiol. 2005, 161, 434-441. [CrossRef]

29. World Health Organization. Occupational health: A Manual for primary health care workers. In Occupational Health: A Manual for Primary Health Care Workers; WHO: Geneva, Switzerland, 2001.

30. Hannerz, H.; Holtermann, A.; Fransson, E. Heavy Lifting at Work and Risk of Ischemic Heart Disease: Protocol for a Register-Based Prospective Cohort Study. JMIR Res. Protoc. 2014, 3, e45. [CrossRef]

31. Glozier, N. Mental ill health and fitness for work. Occup. Environ. Med. 2002, 59, 714-720. [CrossRef]

32. Follmer, K.B.; Jones, K.S. Mental Illness in the Workplace: An Interdisciplinary Review and Organizational Research Agenda. J. Manag. 2017, 44, 325-351. [CrossRef]

33. World Health Organization. Mental Health in the Workplace. Available online: https://www.who.int/mental_ health/in_the_workplace/en/ (accessed on 30 August 2020).

34. Matranga, D.; Restivo, V.; Maniscalco, L.; Bono, F.; Pizzo, G.; Lanza, G.; Gaglio, V.; Mazzucco, W.; Miceli, S. Lifestyle Medicine and Psychological Well-Being Toward Health Promotion: A Cross-Sectional Study on Palermo (Southern Italy) Undergraduates. Int. J. Environ. Res. Public Health 2020, 17, 5444. [CrossRef] [PubMed]

35. Ergün, D.; Ergun, R.; Ergan, B.; Kurt, O.K. Occupational Risk Factors and the Relationship of Smoking with Anxiety and Depression. Turk. Thorac. J. 2018, 19, 77-83. [CrossRef] [PubMed]

36. Stansfeld, S.A.; Rasul, F.R.; Head, J.; Singleton, N. Occupation and mental health in a national UK survey. Soc. Psychiatry Psychiatr. Epidemiol. 2009, 46, 101-110. [CrossRef]

37. Michie, S. Reducing work related psychological ill health and sickness absence: A systematic literature review. Occup. Environ. Med. 2003, 60, 3-9. [CrossRef] [PubMed]

38. Wang, J. Work stress as a risk factor for major depressive episode(s). Psychol. Med. 2005, 35, 865-871. [CrossRef] [PubMed] 
39. Hiesinger, K.; Tophoven, S. Job requirement level, work demands, and health: A prospective study among older workers. Int. Arch. Occup. Environ. Health 2019, 92, 1139-1149. [CrossRef] [PubMed]

40. World Health Organization. Mental Health Policies and Programmes in the Workplace; WHO: Geneva, Switzerland, 2005.

Publisher's Note: MDPI stays neutral with regard to jurisdictional claims in published maps and institutional affiliations.

(C) 2020 by the authors. Licensee MDPI, Basel, Switzerland. This article is an open access article distributed under the terms and conditions of the Creative Commons Attribution (CC BY) license (http://creativecommons.org/licenses/by/4.0/). 